\title{
Estrategias de investigación en materia de archivos audiovisuales televisivos
}

Jorge Caldera Serrano

Universidad de Extremadura (España)

\section{Blas Benítez Jaramillo}

Centro de Fomento de Nuevas Iniciativas. Junta de Extremadura (España)

\section{Resumen}

Se enumeran y explican las principales líneas de investigación que sobre los archivos de televisión se desarrollan en el ámbito de la Information Science. La discusión se organiza en dos grandes bloques: pautas generales y políticas de actuación e investigación tecnológica. Para cada uno de ellos, se analizan aspectos tales como selección, ética, conservación y preservación, derechos, terminología, formación profesional, así como los procesos de digitalización y asignación de metadatos.

Palabras clave: Documentación audiovisual. Televisión. Gestión de la información. Digitalización. Streaming. Metadato. MPEG. Investigación.

\begin{abstract}
The main research lines on the television archives are outlined, explained and considered from the point of view of the Information Science. These research parcels are organized into two parts: general information and political guidelines and technological research. In both sections, aspects such as selection, ethics, conservation and preservation, rights, terminology, professional formation, digitization processes and metadata are analyzed.
\end{abstract}

Keywords: Audiovisual documentation. Television. Information management. Digitalization. Streaming. Metadata. MPEG. Research.

\section{Introducción}

Son muchos los autores que opinan que las ciencias de la documentación son una disciplina en formación, que aún son muchos los elementos conceptuales, técnicos, éticos y terminológicos que deben definirse a la vista de la rápida evolución tecnológica, lo que hace necesario una continua revisión y adaptación de métodos y estrategias documentales que podrían preverse como estables. Aunque son

Scire. $11: 2$ (sep.-dic. 2005) 153-164. ISSN 1135-3761. 
numerosos los trabajos del área de biblioteconomía y documentación que se encargan de los centros de información tradicionales (bibliotecas, centros de documentación y archivos), son escasos los dedicados a centros que no siguen las pautas tradicionales de las unidades informativas reseñadas. Los archivos de televisión son un claro ejemplo de aquellos subapartados de la documentación que aún están por desarrollar, siendo ahí donde realmente se observa la necesidad de seguir desarrollando labores de actualización al amparo de la rápida evolución tecnológica, como los nuevos parámetros aportados por la tipología documental específica, los diferentes ítems documentales y muy especialmente las peculiaridades de los usuarios, los cuales han de marcar los objetos y estrategias de cualquier unidad documental.

Las distintas definiciones sobre el propio concepto de audiovisual clarifican las dos corrientes existentes. La primera de ellas define lo audiovisual como la existencia de la imagen o el sonido, integrando por lo tanto información sonora y de imagen fija; la segunda idea muestra como necesaria la existencia de ambas bandas, visual y sonora, contando por tanto con la documentación televisiva y fílmica. Por su parte, Alfonso López Yepes (1992, p. 23) define documentación audiovisual como la "ciencia que tiene por objeto el estudio del proceso de comunicación de las fuentes audiovisuales para la obtención de nuevo conocimiento aplicado a la investigación y el trabajo audiovisual", aclarando posteriormente el concepto especificando el objeto de trabajo —el documento audiovisual:

[... ] como documento científico que es, participa por consiguiente de las mismas notas de información y de fuente informativa y se integra igualmente en el proceso informativo-documental: emisor (documentalista audiovisual), canal o medio de transmisión (soporte audiovisual), mensaje (documento audiovisual), receptor o usuario del mensaje (del documento audiovisual).

Antonio Hernández Pérez $(1992,108)$ igualmente lo define como "aquel conjunto de mensajes cuyo contenido lo constituyen básicamente imágenes en movimiento acompañadas, de forma más o menos sincrónica, por elementos del sistema sonoro — voces, música, ruidos-". El Manual de documentació audiovisual en ràdio i televisió $(1999$, p. 18) ofrece una definición más acertada: "La documentació audiovisual podria considerar-se com aquell conjunt de missatges el contingut dels quals el constitueixen básicament imatges en moviment (banda imatge) acompanyades per elements del sistema sonor: veus, música, sorolls (banda so)".

Con la trascripción de estas definiciones se desea demostrar lo complejo de un concepto poco conocido, que se traduce en unas técnicas y tácticas documentales específicas y complejas, que hacen de la labor del documentalista audiovisual una tarea atractiva, con elementos que lo caracterizan y lo diferencian del resto de documentos y labores profesionales. 


\section{Investigación y televisión}

Son diferentes los procesos y puntos de vista desde los que se puede abordar la investigación en el ámbito televisivo. Tan solo se van a analizar los elementos derivados de la gestión documental de información de imagen en movimiento en los departamentos o servicios documentales de las cadenas televisivas.

Se va a partir de una doble funcionalidad en la implementación y desarrollo de diferentes investigaciones. Por un lado, es posible desarrollar labores investigadoras por y para un único centro, una única empresa; por lo que el desarrollo, gastos, pagos de recursos humanos y adquisición de maquinaria operativa correrá a cargo de una única empresa que contará con la exclusividad de los resultados sin que sea posible su comercialización y sin la posibilidad de acceder a la metodología empleada y resultados operativos (tecnológicos-documentales) novedosos surgidos al amparo de dicha investigación. Por otra parte, una segunda manera de entender la investigación viene marcada por la unión de diferentes entidades con el fin de cooperar o intercambiar resultados y productos.

Debe quedar aquí claramente reflejado que la gestión de la información en el marco de las empresas audiovisuales se encuentra enmarcado en la teoría del Information Management System, donde la información es tomada como un activo empresarial con idéntica valía a los recursos económicos y los recursos humanos, siendo un factor implicado en el círculo productivo de información-dinero-poder. Siguiendo con la argumentación, parece complicado que se produzca una coordinación efectiva entre televisiones al ser empresas que conforman una clara competencia. La realidad nos hace patente dicha hipótesis, ya que la relación entre las cadenas es mínima en el ámbito de la coordinación y cooperación investigadora, y todo ello partiendo de una realidad, la existencia de organizaciones supranacionales que coordinan dichas empresas televisivas. La Unión Europea de Radiodifusión es un claro ejemplo, así como la Federación Internacional de Archivos de Televisión, ambas con amplio calado entre las cadenas televisivas europeas y norteamericanas; y, sin embargo, con escasa presencia en el desarrollo de la investigación conjunta. Por lo tanto, el desarrollo de las investigaciones para la creación de herramientas y mejora de la calidad documental suele llevarse a cabo por las empresas (investigación aplicada), mientras que una investigación teórica suele venir de la mano de las grandes instituciones que se han mencionado con anterioridad.

El caso español es dispar atendiendo a la cadena. Recientemente Telecinco ha comenzado una apertura en sus métodos de investigación llevando a cabo proyectos de investigación conjuntos con la Universidad Complutense de Madrid y comenzando conversaciones con otras. Sin embargo, siguen siendo las propias cadenas las que desarrollan sus investigaciones. Por consiguiente, y a la vista de esta diferenciación entre investigación técnica, teórica y de gestión, se van a describir las principales líneas de investigación en esta materia.

Scire. 11 : 2 (sep.-dic. 2005) 153-164. ISSN 1135-3761. 


\section{Pautas generales, políticas de actuación y gestión}

En primer lugar, se parte de una clasificación por medio de grandes "centros de interés" en materia de investigación en el ámbito de los archivos audiovisuales. Para ello se han analizado los diferentes estudios de entidades supranacionales, así como de grupos de investigación y cadenas nacionales. Hay que volver a señalar lo complicado de acceder a la información y a los proyectos en marcha de las cadenas, lo que debe resolverse gracias a contactos personales y nunca a los institucionales.

Se echa en falta en el Estado español un organismo que trabaje en materia de lo audiovisual, un instituto que además de servir como depósito legal de lo sonoro y lo visual español sirva como centro de investigación y desarrollo de estándares válidos. Igualmente lamentable es la ausencia de una asociación que aglutine a investigadores y trabajadores de la incipiente disciplina de lo audiovisual.

\subsection{Políticas y criterios de selección}

Pudiera entenderse como superado el estudio en tales actuaciones, aunque la realidad muestra que no está finiquitado en el ámbito de la documentación audiovisual. Sigue siendo necesaria la creación de políticas generales para el desarrollo de los Sistemas de Información Documental, determinando los criterios de selección, adquisición y elementos referidos a las políticas generales de la empresa.

Estas pautas intentan desarrollarse en entidades internacionales; sin embargo, las cadenas no pueden asumir como suyos estos criterios y parámetros sin una valoración previa; en muchos casos tales políticas son desechadas en su totalidad o en parte por no cumplir con los requerimientos y políticas de la cadena, siendo necesario un reajuste a la vista de los recursos humanos y técnicos propios.

\section{2. Ética y deontología profesional}

Dicha línea está presente como desarrollo teórico en la mayor parte de las entidades supranacionales, no así en las cadenas que laboran con el material audiovisual. La ética, a veces tomada como cuestión individual, debe tratarse con parámetros científicos y serios, sistematizando procesos y métodos para hacer un correcto uso y mejorar así el funcionamiento de las diferentes partes del sistema de información. De todas maneras, los parámetros y valores éticos reflejados como generales por las entidades no tienen una gran utilidad en empresas concretas, que deben valorarlos individualmente, aunque sí puedan servir como elementos a tener en cuenta en la formación de nuevos profesionales.

Los elementos éticos deben estar cohesionados por diferentes parámetros, entre los que destaca la legislación que sobre derecho a la intimidad y a la información exista en cada comunidad social. El marco en el que ha de moverse cualquier documentalista siempre debe ser el estatuto legal de cada uno de los países, más que 
pretender organizar la ética por parámetros morales o religiosos inherentes a cada una de las personas, en la que los documentalistas no son excepción. Estos elementos legales sobre todo han de ser tenidos en cuenta en el momento de la configuración del fondo, previendo la reutilización futura así como la preservación de un patrimonio que no únicamente es de la cadena, sino también del Estado que lo sustenta socialmente (televisiones públicas) o de las que son un fiel y claro reflejo (televisiones públicas y privadas).

\subsection{Conservación y preservación}

Uno de los grandes proyectos en los que se han implicado las organizaciones supranacionales, entre las que destaca la UNESCO, es la conservación de soportes y formatos, así como la preservación de archivos audiovisuales tanto de carácter estatal como privados.

En lo referente a la preservación es muy necesario el conocer las características físicas y químicas de los soportes para poder salvaguardar formatos y soportes dispares. La recuperación, restauración y conservación del material audiovisual en formatos analógicos se traduce en un gran esfuerzo derivado de los problemas químicos inherentes al soporte, que hace que su degradación sea rápida y con escasas posibilidades de recuperación con integridad total. Estos proyectos y desarrollos de estándares de conservación van encaminados especialmente a aquellos países con escasa capacitación técnica y humana, aportando así parámetros para la conservación del patrimonio audiovisual de los Estados en vías de desarrollo. La falta de cultura documental, unida a las escasas posibilidades económicas y a la reducida capacitación profesional, hace necesarias intervenciones de carácter supranacional para la salvaguarda de dicha información.

Las diferentes vías de investigación deben desarrollarse atendiendo a la rápida evolución y obsolescencia de los soportes digitales, replanteando métodos que abarcan desde la producción hasta la conservación.

\subsection{Depósito legal}

El intento de desarrollo legislativo de diferentes países es uno de los pilares en los que se fundamenta la conservación patrimonial de lo audiovisual. El intento por algunas entidades de institucionalizar la conservación viene avalado por variados estudios y proyectos de conservación definitiva y estable en diferentes zonas del planeta. No se debe creer que la ausencia de depósito legal para el material de imagen en movimiento es una carencia propia de los países en vías de desarrollo, sino que también es inexistente en muchos países "desarrollados", entre ellos España. Esto supone que la conservación de dicha información queda al amparo de la buena voluntad de las empresas audiovisuales.

Por lo tanto, la creación de un depósito legal de lo audiovisual y de una institución que haga que se lleve a buen fin debe venir prefijada por una legislación

Scire. 11 : 2 (sep.-dic. 2005) 153-164. ISSN 1135-3761. 
que en materia de conservación sea útil y ágil. El caso español cuenta con la Ley de Patrimonio, que, sin embargo, no trata de manera clara la conservación de lo audiovisual, ni se ha vertebrado con posterioridad una legislación que posibilite dicho desarrollo.

\subsection{Terminología}

Parece necesaria la puesta en marcha de estándares comunes pero también de la implementación de una terminología universal para un mejor entendimiento entre profesionales e investigadores. La realidad actual nos muestra la variación terminológica para diferentes conceptos en el ámbito periodístico y, por lo tanto, en su vertiente documental. Tan variada terminología no aporta claridad ni a la sociedad ni a la comunicación fluida, por lo que ya se han llevado a cabo diccionarios terminológicos y conceptuales en materia periodística y televisiva, aunque siga siendo necesaria la implementación de nuevos estudios.

\subsection{Formación profesional}

La formación continua y profesional es uno de los temas de debate y discusión constante en los ambientes asociativos e institucionales en materia de lo audiovisual. Existe una clara necesidad de sentirse un colectivo distinto - que no distante-, como consecuencia de las diferentes técnicas, tácticas y maneras de entender la documentación adaptando sus principios a esta realidad empresarial. Dicha necesidad se ve además avalada por la imperiosa necesidad de regular una capacitación profesional que enseñe las peculiaridades del documento audiovisual y de su tratamiento. Y es que la creación de una figura profesional distinta a las actuales hace necesario que también la formación deba adaptarse. Dicha formación se encamina en dos direcciones diferentes: la primera de ellas, la universitaria, donde se observa la necesidad de incluir asignaturas sobre dicha temática; y, en segundo lugar, una formación continua con programas de perfeccionamiento documental para los profesionales una vez se encuentran en activo en las labores cotidianas dentro de una institución concreta.

$\mathrm{Al}$ entender la documentación de una forma un tanto particular, suele llegarse a la conclusión de la necesidad de crear asociaciones en las que se aglutine a un colectivo disperso geográficamente e institucionalmente, pero con una problemática común que debe ser tratada con criterios profesionales en estos ámbitos de coordinación y discusión.

\subsection{Explotación de los archivos de televisión}

Es doble la necesidad de controlar la explotación de los archivos: por un lado, desde el punto de vista comercial; por otro, desde el institucional. Así, la puesta en marcha de estos servicios parte de un origen funcional, que es la de aportar la información solicitada por unos usuarios específicos: los periodistas de las cadenas 
televisivas. Esto marca todo el proceso de gestión documental y también del marco explotacional del archivo. Se desea reflejar que el archivo está claramente al servicio de unos usuarios altamente especializados y conocedores de su profesión. El documentalista es un servidor que a su vez está encuadrado dentro del proceso productivo de la obra audiovisual televisiva. Por lo tanto, una primera explotación será la interna, llevada a cabo por el personal de la empresa. Por otro lado, es evidente que el archivo es un activo patrimonial de la cadena, pero es igualmente incuestionable su valor como activo económico. La explotación comercial por medio de la venta a terceros está siendo una opción que cada vez se toma más en cuenta por parte de dichas empresas, por lo que se debe regular tanto la difusión física y los costes de producción como los elementos derivados de los derechos de explotación y comercialización, atendiendo a parámetros como quién compra y para qué va a ser utilizada la información.

\section{Investigación tecnológica}

El desarrollo de las tecnologías de la información y la comunicación ha hecho que, junto a la investigación en materia de gestión documental, se haga necesaria la implementación de la labor investigadora en el campo de las tecnologías audiovisuales, como resultado en gran medida de la evolución en las formas y métodos de hacer televisión. La digitalización de la producción, y por lo tanto de las redacciones, hace inevitable el diseño de nuevos métodos de gestión que se adapten a una realidad asumida ya por parte de nuestros usuarios: el entorno digital. Como resultado, el documentalista ha tenido que adaptarse a esta nueva realidad digital asumiendo, integrando y adaptando a sus labores técnicas estas nuevas herramientas.

\subsection{Digitalización}

La digitalización no es un proceso reciente, sino que se está desarrollando desde las dos últimas décadas del siglo pasado, y aún no ha concluido. La investigación está encaminada tanto desde el punto de vista de los requerimientos técnicos como de los tecnológicos, e, incluso, filosófico-éticos en la forma de hacer y entender la documentación. Y es que en esta sociedad de la información la digitalización está alcanzando un notable desarrollo, ya que toda información digital tiene mayor visibilidad, alcance y universalidad en su difusión. Ahora bien, para que dicho proceso de digitalización pueda llevarse a cabo son necesarios la creación y el desarrollo de diferentes software y hardware informáticos, intentando crear métodos y herramientas que agilicen y faciliten dicho proceso, asunto que - a la vista de los procesos de digitalización en marcha- no está exento de problemas.

Son numerosos los problemas que surgen del proceso de digitalización; sin embargo, sería equívoco el pensar que los principales problemas vienen derivados de Scire. $11: 2$ (sep.-dic. 2005) 153-164. ISSN 1135-3761. 
los procesos técnicos o de la individualidad de los formatos, ni tan siquiera de los recursos humanos o tecnológicos necesarios; el principal problema es la revolución social, metodológica y filosófica de entender y acceder a la información.

Otros de los problemas que se evidencian es la falta de formatos y estándares correctos tanto para la captación como para la reproducción. La lucha entre las marcas comerciales hace problemática e incierta la toma de decisiones sobre la adopción de sistemas.

Se deben destacar también los problemas derivados de la migración de los fondos analógicos a lo digital. Evidentemente no todas las empresas surgen y se desarrollan en entornos digitales, sino que nacen en décadas anteriores, en las que se utilizaron otros tipos de formatos. El problema, por tanto, viene tanto de la cantidad impresionante de horas captadas como por la falta de reproductores y técnicos que puedan realizar esta labor de forma eficiente y oportuna. Las empresas dedicadas a los procesos de digitalización cuentan igualmente con graves problemas en dicha migración al no estar siempre preparadas para realizar una manipulación y reproducción de la información que garantice la integridad física de la obra audiovisual.

\subsection{Tecnologías para la transmisión de información audiovisual por web}

La inevitable transformación de la televisión hacia el mundo digital está poniendo de manifiesto la necesidad de nuevas vías de explotación, una de las cuales es la difusión por Internet, que se estima como el potencial medio de transmisión de la información más importante no solo en un futuro cercano, sino claramente como apuesta en nuestro presente.

Una de las tecnologías para la difusión de la información audiovisual por medio de la red es el media streaming, que es a la vez extremadamente sencilla y cómoda, ya que posibilita el visionado sin que se tenga que esperar a la descarga completa del archivo, contando con las medidas de seguridad necesarias para que el usuario no pueda conservar dicha información en ningún tipo de dispositivo. Para los departamentos de documentación audiovisual supone una nueva herramienta de difusión a través de las intranets corporativas, distribuyendo la información de forma rápida y efectiva, sin un coste informático importante (desde el punto de vista de la carga de conservación ni ocupación de las líneas) y sin que se interrumpa el desarrollo normal de la organización. Esta tecnología no es solo útil para los usuarios finales, sino para usuarios externos del Sistema de Información Documental, es decir, otras televisiones, agencias de información o cualquier usuario potencial que quiera acceder a los registros documentales de la empresa.

La posibilidad de elegir el producto que se desea y disfrutarlo en el momento requerido, pagando por ello un canon por la tipología del producto o el tiempo visionado - pay per view —, va a ser otro de los grandes potenciales de la televisión por red, que lo va a acercar al concepto de "televisión a la carta".

Scire. 11 : 2 (sep.-dic. 2005) 153-164. ISSN 1135-3761. 
Existen dos formas de acceder o difundir la información por media streaming. En primer lugar, el vídeo bajo demanda, en el que el cliente, usuario o receptor identifica cuál es el clip que desea visionar de una serie de documentos relacionados. La concurrencia de visionados $-\mathrm{y}$, por lo tanto, de acceso al documento- dependerá del tipo de servidor con el que se trabaje o se tengan contratados los servicios streaming. En segundo lugar, la emisión en directo, en la que los usuarios deben conectarse en el horario determinado y prefijado por la empresa televisiva. Por lo tanto, se trata de una reproducción y captación en tiempo real.

Además de estas dos formas, el streaming se puede clasificar atendiendo a los protocolos utilizados para la transmisión de dos maneras. La primera, conocida como falso streaming, es utilizada por los protocolos HTTP y TCP/IP para el envío de información audiovisual, utilizando los mismos protocolos que las páginas web, siendo válido tanto para Real Media como Windows Media, garantizando la visión del clip, aunque es necesario contar con un espacio en el disco duro en el que almacenar los pequeños fragmentos del documento. En la segunda, el true streaming, el archivo audiovisual se ubica en el servidor que envía la información.

\subsection{Universal Mobile Telecommunications System (UMTS)}

Con anterioridad se analizaba el principal desarrollo en la investigación de información audiovisual para la transmisión de datos; ahora se va a mencionar brevemente otra línea de investigación marcada por el novedoso soporte físico para la transmisión de la información, la tecnología UMTS. Esta es la tercera generación de dispositivos móviles y va a suponer —o está suponiendo — una revolución tecnológica utilizada por las principales operadoras de telefonía y próximamente por las principales cadenas de televisión. Consiste en la creación de una banda ancha de 2 mbps para móviles o cualquier dispositivo portátil, ya sea PC o PDA conectado a dicha red, lo que va a dar a los usuarios la posibilidad de acceder a los contenidos con una gran movilidad y riqueza de información.

\subsection{Descomposición de vídeo}

Otra línea de investigación, unida a los procesos de digitalización, producción y realización en línea, es la descomposición automática de vídeo en fragmentos con los que posteriormente se deberá elaborar la unidad documental de conservación y de tratamiento. Las principales líneas de trabajo son tres:

a) Descomposición temporal. Se lleva a cabo sobre el documento sin montar en forma secuencial, tanto sobre la banda sonora como sobre la banda visual. No contiene elementos externos, como editados o postproducción, por lo que la división del documento audiovisual se lleva a cabo a partir de los cortes, fundidos, cambios de secuencias, etc. Dicha técnica aún plantea graves problemas, aunque es la más difundida gracias a la comercialización de los paquetes de software que utilizan dicha tecnología.

Scire. $11: 2$ (sep.-dic. 2005) 153-164. ISSN 1135-3761. 
b) Análisis gráfico de imágenes. Descompone la imagen para que sea analizada por el software atendiendo a parámetros tales como los bordes, colores, textura y densidad, etc. Este método sería el más cercano a la forma de captación del ojo humano.

c) Descomposición espacial. Se separa la imagen en los diferentes elementos que la constituyen. Realmente, es una mezcla entre los modelos anteriormente mencionados. Su utilidad informática sigue desarrollándose debido a los muchos problemas técnicos que plantea su utilización.

\subsection{Metadatos}

Es necesario adaptar nuestro clásico modelo de descripción con puntos de acceso a esta nueva realidad tecnológica. Conceptualmente metadatos significa "datos de datos" (Peig Olive, 2003), es decir, datos extraídos del análisis del documento; por ejemplo, Dempsey (1996) señala que es un término torpe que sirve para designar los datos que ayudarán en la identificación de un recurso, dígase descriptores, palabras claves, catálogos, en definitiva, puntos de acceso a los documentos.

El término metadatos no es concepto novedoso para los documentalistas, ya que se lleva extrayendo puntos de acceso desde la creación de las primeras bibliotecas. Ahora bien, el auge de las TIC está propiciando un crecimiento hasta ahora desconocido de material audiovisual presente en la red. Y la televisión no está al margen de este medio, ya que, como se ha mencionado anteriormente, la red va a posibilitar nuevas realidades de negocio. Sin embargo, para que dicho punto sea una realidad se hace necesaria una reconversión de las técnicas y hábitos de gestión de lo analógico hacia la cultura digital.

La estandarización de estos elementos tiene su origen en el formato MARC en los años sesenta como sistema de intercambio de registros bibliotecarios. Actualmente la generalización del uso de Internet marca un punto de inflexión en los metadatos, ya que toda información digital lleva consigo una serie de metadatos asociados que permiten su recuperación entre la maraña de Internet. Estos pueden ser desde las etiquetas de $<$ META $>$ de una página web hasta los MPEG en sus diferentes versiones, que llegan a describir un proceso o una acción.

\subsection{Motion Picture Experts Group (MPEG)}

Uno de los proyectos de estandarización para la codificación e intercambio de información multimedia, y más concretamente la audiovisual, es el MPEG. Dicho estándar es el resultado de los trabajos del comité que le da nombre: el Motion Picture Experts Group (MPEG) de ISO/EIC.

Los primeros resultados de este grupo fueron el MPEG1 (almacén y descarga de archivos audiovisuales) y el MPEG2 (televisión digital), publicados en 1992 y 1994 respectivamente. En ellos se establece la base para la codificación, alma- 
cenamiento y transmisión de información multimedia, siendo los estándares más difundidos para mp3, Vídeo CD y el Digital Audio Broadcasting.

MPEG 4 aparece en 1999. En él se introduce la noción metadatos para facilitar la representación desde el punto de vista del contenido, añadiendo una capa semántica para poder acceder a la información audiovisual. Este avance facilita enormemente el proceso de interacción con el usuario a la hora de la recuperación, sirviendo de base para la televisión digital — televisión a la carta—, la transmisión por streaming o la tecnología UMTS.

La última versión de los estándares anteriores la encontramos en el MPEG 7, publicado como norma internacional en 2001. Este nuevo modelo incluye en su estructuración el concepto novedoso de descriptor como representación de una propiedad de la información audiovisual que muestra el contenido en alguna de sus facetas. A partir de este momento es cuando podemos hablar de metadatos y MPEG. Aunque el MPEG está pensado para el contenido audiovisual, puede también ser utilizado para material gráfico, sonoro, información en tres dimensiones, animaciones y en definitiva cualquier tipo de montaje multimedia. Utiliza esquemas de descripción del Lenguaje de Definición de Descriptores (DDL), definido igualmente por MPEG, que usa como base el lenguaje XML Schema. Este lenguaje (DDL) aporta gran flexibilidad para la identificación de elementos descriptivos no definidos con anterioridad. Por lo tanto, el MPEG-7 permite la descripción por palabras claves y por significación semántica de los contenidos, además de aportar los elementos estructurales del documento, ayudando así a las herramientas de indización para la creación de grandes gestores de información audiovisual.

El MPEG sigue trabajando sobre el estándar inacabado MPEG-21, el cual aporta algunas soluciones, pero sigue mostrando excesivas deficiencias. Este nuevo estándar está especialmente orientado a presentar un entorno global desde el punto de vista de la infraestructura necesaria para la distribución y uso de contenidos digitales, abarcando sus distintos aspectos: producción, descripción, gestión, protección y acceso.

Se ha de reflejar también la evolución hacia otros nuevos estándares válidos y flexibles para la especificación de metadatos con elementos audiovisuales como el Synchronized Multimedia Integration Language (SMIL). Este, sin embargo, está sin desarrollar en toda su faceta documental, planteando variados retos y una ilusionante incertidumbre.

\section{Conclusiones}

Una vez descritas las principales líneas de investigación en lo que los archivos de televisión se refiere, se ha de aclarar que se han mostrado las principales estrategias de investigación directamente relacionadas con la temática planteada. Sin

Scire. $11: 2$ (sep.-dic. 2005) 153-164. ISSN 1135-3761. 
embargo, son muchas las áreas del conocimiento con las que la investigación en dicha materia está vinculada. El continuo desarrollo en otras disciplinas - especialmente en computación y comunicación - hace necesaria una continua adaptación y reconversión de los planes investigadores. La horizontalidad experimental en dicha materia debe quedar patente y reflejada en los distintos grupos de investigación, que suelen estar sustentados tanto por ingenieros de computación como por documentalistas, sin olvidarnos de otro tipo de profesionales que pudieran ayudar al desarrollo de algún aspecto concreto.

Es cierto que aún quedan muchas cosas por hacer, pero igualmente seguro es que en dicha materia se ha comenzado a investigar muy recientemente, como demuestran las escasas publicaciones existentes. Sin embargo, dicho bagaje científico es aún más escaso en nuestro Estado, en el que se observan muy pocas aportaciones de profesionales; igualmente paupérrimas son las aportaciones por parte de los docentes de las universidades españolas.

Se debe señalar, en último lugar, la necesidad de seguir desarrollando investigaciones aplicadas que ofrezcan soluciones a problemas reales; pero igualmente parece necesario facilitar un aporte teórico a una disciplina que no solo es novedosa, sino que requiere una gestión documental peculiar tanto por la naturaleza de lo audiovisual como por el uso que de esta documentación hacen los usuarios.

\section{Referencias}

Caldera Serrano, Jorge (2004). Utilización de metadatos para la descripción documental y recuperación de material audiovisual en los archivos televisivos. // Legajos: Cuadernos de Investigación Archivística y Gestión Documental. 7 (2004).

Dempsey, Lorcan (1996). Meta Detectors. // Ariadna. 3( mayo-1996). URL: <http://www. ariadne.ac.uk/isue3/metadata>. Consultado: 2004-12-01.

Hernández Pérez, Antonio (1992). Documentación audiovisual: metodología para el análisis documental de la información periodística audiovisual. Madrid: Universidad Complutense, 1992.

López Yepes, Alfonso (1992). Manual de documentación audiovisual. Pamplona: Universidad de Navarra, 1992.

Manual de documentació audiovisual en ràdio i televisió (1999). Valencia: Universitat, 1999.

Menéndez Rodríguez, Eva (2002). Metadatos y recuperación de información: estándares, problemas y aplicabilidad en bibliotecas digitales. Gijón: Trea, 2002.

Peig Olivé, Enric (2003). Interoperabilidad de metadatos en sistemas distribuidos. Barcelona: Universitat Pompeu Fabra, 2003.

Scire. 11 : 2 (sep.-dic. 2005) 153-164. ISSN 1135-3761. 